\title{
Improving the voltage quality of Abu Hummus network in Egypt
}

\author{
Ibrahim A. Nassar ${ }^{1}$, Mohammed Sh. Seif ${ }^{2}$, Mahmoud M. Elattar ${ }^{3}$ \\ 1,2Department of Electrical Engineering, Faculty of Engineering, Al-Azhar University, Egypt \\ ${ }^{3}$ Behira Company for Electricity Distribution, Ministry of Electricity and Renewable Energy, Egypt
}

\begin{tabular}{|c|c|}
\hline Article Info & ABSTRACT \\
\hline Article history: & \multirow{9}{*}{$\begin{array}{l}\text { In this paper the performance of the electrical network of Egypt is studied } \\
\text { by considering a small part on the network (Abu Hummus city). } \\
\text { The transmission network of Abu Hummus city was created for } 66 \mathrm{kV} \text {, } \\
11 \mathrm{kV} \text {, and } 0.4 \mathrm{kV} \text { in the digital simulation and electrical network calculation } \\
\text { (DIgSILENT power factory software) to study the voltage profiles. The load } \\
\text { flow operational analysis was performed to obtain the voltage magnitudes } \\
\text { at every bus bar. The voltage magnitudes in } 11 \mathrm{kV} \text { and } 0.4 \mathrm{kV} \text { networks } \\
\text { were } 10 \% \text { to } 15 \% \text { less than the nominal value due to overloading off } \\
\text { the transmission lines and the voltage magnitudes in } 66 \mathrm{kV} \text { was within } \\
\text { permissible limits. By using automatic tap-changing transformer or Static } \\
\text { VAR System, the main idea of this paper is to obtain the voltage profiles at } \\
\text { every bus bar to improve the voltage quality of the networks, so as to achieve } \\
\text { better voltage profiles on the low voltage side without much effect on high } \\
\text { voltage side under various operating conditions. }\end{array}$} \\
\hline Received Sep 11, 2019 & \\
\hline Revised Mar 18, 2020 & \\
\hline Accepted Mar 28, 2020 & \\
\hline Keywords: & \\
\hline Automatic tap-changer & \\
\hline Network & \\
\hline Static VAR system & \\
\hline Voltage quality & \\
\hline
\end{tabular}

Copyright $@ 2020$ Institute of Advanced Engineering and Science. All rights reserved.

\section{Corresponding Author:}

Ibrahim A. Nassar,

Department of Electrical Engineering,

Faculty of Engginering, Al-Azhar University,

Al Nasr Road, opposite to Cairo International Conference Center, Nasr City 11751, Egypt.

Email: ibrahim.nassar@azhar.edu.eg

\section{INTRODUCTION}

Egypt's electricity grid was suffering in power generation and distribution losses from 2006 to 2012 becouse generating capacity was less than the power consumed [1] at the end of 2013, a new era has begun in the energy generated for the Egyptian network. The nominal capacity of the network was increased by the end of 2013 to about $32 \mathrm{GW}$ with a maximum load of about $26 \mathrm{GW}$, At the end of 2015, it was about $35 \mathrm{GW}$, with a maximum load of about $28 \mathrm{GW}$, At the end of 2016, it was about $38 \mathrm{GW}$, with a maximum load of about $29.2 \mathrm{GW}$, At the end of 2017, it was about $45 \mathrm{GW}$, where the maximum load was about $29.4 \mathrm{GW}$ [2]. At the end of 2018, nominal capacities have been added to the public network due to the addition of generating units and stations for operation, which ensures the stability of the quality of nutrition for the Egyptian electricity network has recently been added $14.4 \mathrm{GW}$, by the addition of stations Berlus, koraumat and administrative capital where the maximum load was about $30.3 \mathrm{GW}$ as shown in Figure 1. As above mentioned the additional nominal capacity of renewable energy, which may reach at the end of 2016, Egypt produced 750 MW of power from wind (approximately 1.9\%). The target for the installed wind power capacity in Egypt is to exceed 7200 MW by 2022, meaning that approximately 600 MW of wind farm capacity is expected to be connected to the Egyptian grid annually. Electricity consumption in Egypt is for industrial, residential, agricultural and other purposes, residential consumption accounts for more than 50 percent of electricity consumption in Egypt demonstrated in Figure 2, the Egyptian electricity grid demonstrated to the electrical system in Egypt, which includes generation, transmission and distribution of different voltage as shown in Figure 3 [3]. The detailed non-linear dynamic model of 
the Egyptian power system was developed. The overview of the power balance of the Egyptian power system with all power plants (gas turbine driven generatorpower plants (GPP), steam turbine power plant (SPP), combined cycle power plant CCPP and hydropower plants (HPP)) is shown in the Figure 4 [4-8].

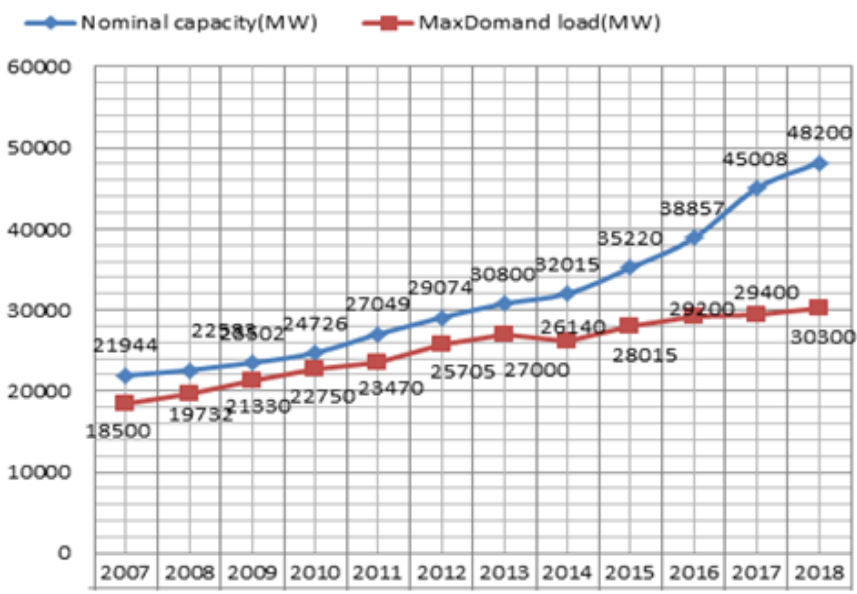

Figure 1. Overview of the nominal capacity and maximum load to Egyptian electricity grid from 2007 to 2018

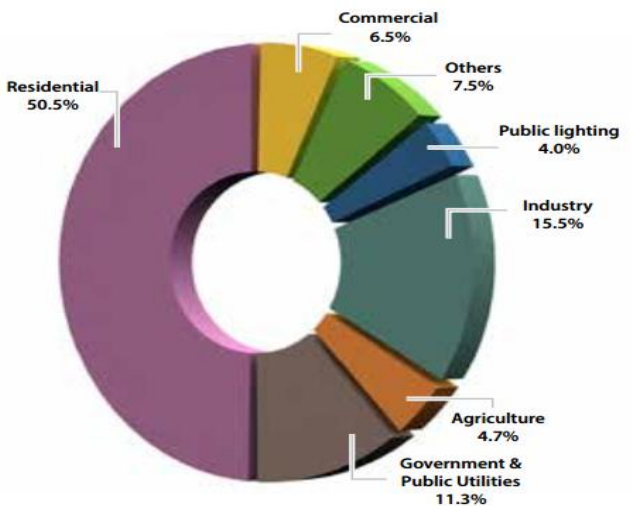

\begin{tabular}{ll}
\hline Purpose of usage & Sold energy (gwh) \\
\hline Industry & 19660 \\
Agriculture & 6033 \\
Government and Public & 14336 \\
Utilities & 64125 \\
Residential & 8272 \\
Commercial & 5115 \\
Public lighting & 9529 \\
Others * & 127070 \\
Total &
\end{tabular}

Figure 2. Overview of the electricity

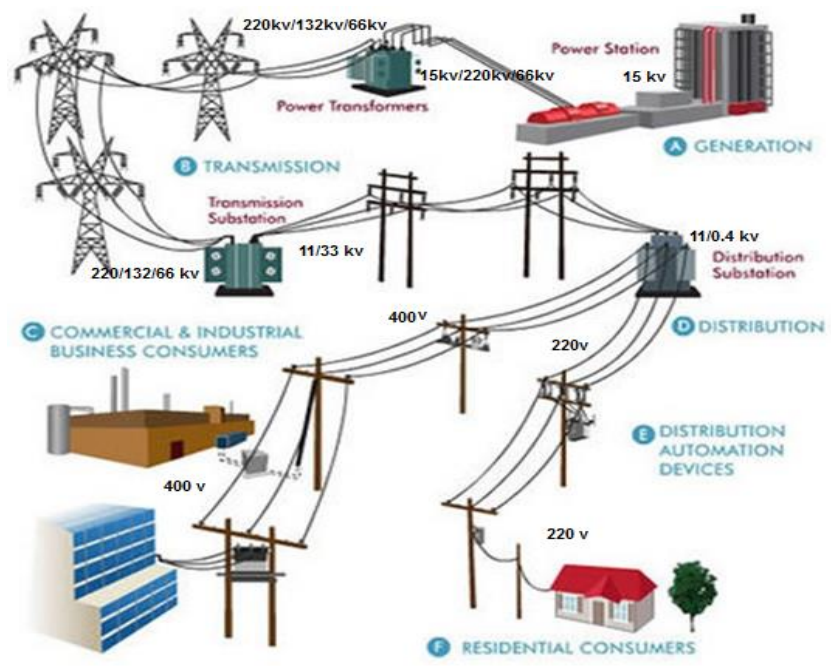

Figure 3. Overview of electrical system in Egypt for generation, transmission and distribution 


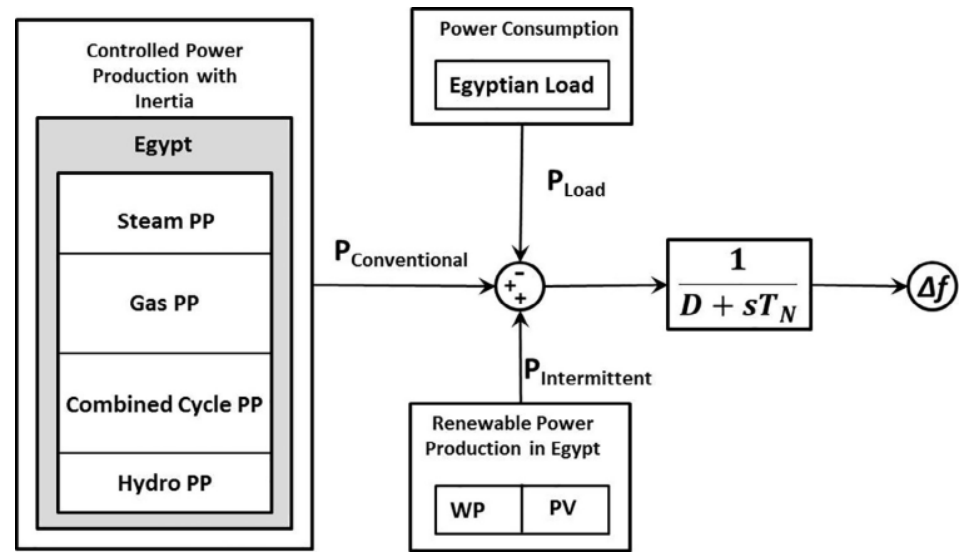

Figure 4. Overview of the power balance of Egyptian power system

Problem of the network Abu Hummus city in transmission networks for $11 \mathrm{kV}$, and $0.4 \mathrm{kV}$ in the digital simulation and electrical network calculation (DIgSILENT power factory software) - and normal measurments. The load flow operational analysis was performed to obtain the voltage magnitudes at every bus bar. The voltage magnitudes in $11 \mathrm{kV}$ and $0.4 \mathrm{kV}$ networks were $10 \%$ to $15 \%$ less than the nominal value due to overloading and used some methods to solution of the problem (the voltage quality) by using: Automatic Tap-Changer, Static VAR Systemof the transmission lines.

\section{NETWORK OF ABU HUMMUS}

Figure 5 shows the transmission and distribution network of Abu Hummus consists of overhead lines operating at various voltage levels ranging from $220 \mathrm{kV}$ to $66 \mathrm{kV}$ and $11 \mathrm{kV}$ respectively. The city is connected directly by two power plants Damanhur and Kafr El Dawar power plant. The city receives power from both stations and external network by substation $220 \mathrm{kV}$ to $66 \mathrm{kV}$ in Kafr El Dawar and Damanhur. The city provides electricity through the main source of Abu Hummus transformer station, which accounts for 80 percent of the electricity source of this city, which contains the number of three transformers of 25 MVA $66 / 11 \mathrm{kV}$, Where the electricity are supplied, which accounts for 80 percent of the electricity source of this city, which contains the number of three transformers of 25 MVA $66 / 11 \mathrm{kV}$, Where the electricity are supplied Form two distribution boards.

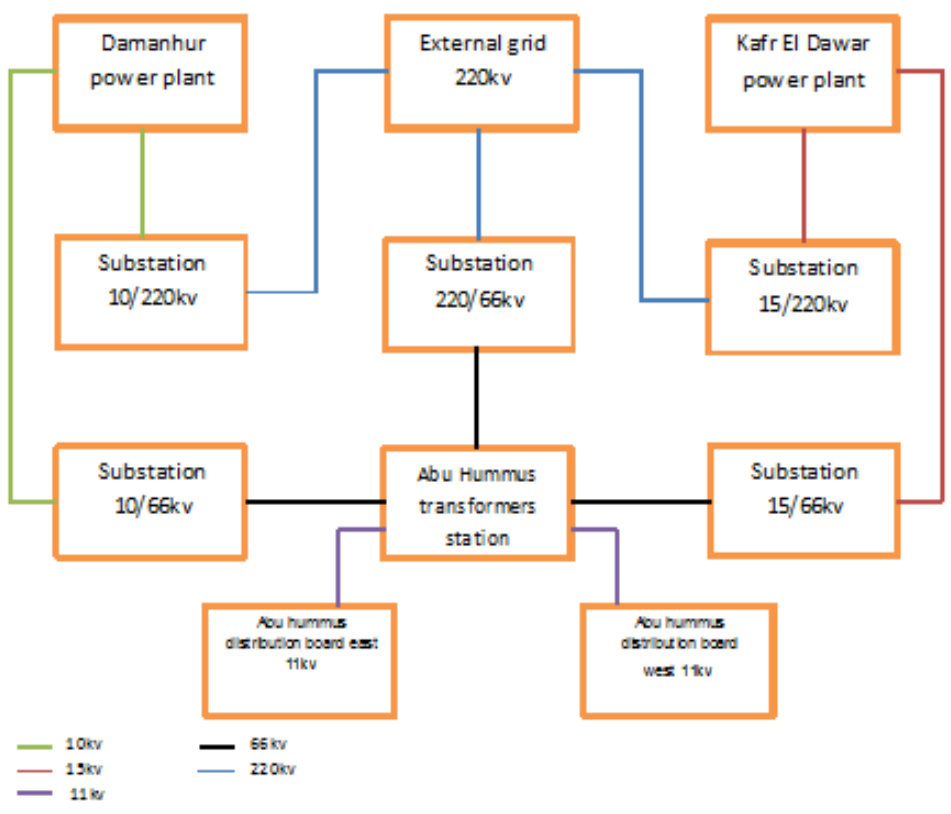

Figure 5. Overview of the transmission and distribution network of Abu Hummus 
Abu Hummus distribution board east, this includes 8 feeders supplying electricity to $55 \%$ of the city. And Abu Hummus distribution board west, which includes 8 feeders supplying electricity to $45 \%$ of the city. Feeders which $11 \mathrm{kV}$ containing 16 feeders in two distribution boards, where the $11 \mathrm{kV}$ feeders are emanated and distributed to various local transformers in the city where the voltages are step-down to 400v or 220v, depending on the consumer end. And there is aprobleme in voltage in the consumers of end connections [9].

\section{MODELLING OF ABU HUMMUS NETWORK IN DIGSILENT POWER FACTORY}

DigSilent PowerFactory is a high end power system analysis tool for applications in transmission, distribution, generation, industrial, and smart grid operations. It has set standards and trends in power system modelling, analysis and simulation. The DigSilent program helps in creating power system designs, by creating all components in a textual database environment and by manually connecting them, thus defining the topology. The more convenient method however, is to use the interactive single line graphics [10, 11]. Figure 6 shown in the overview of modelled grid of Abu Hummus in DigSilent.
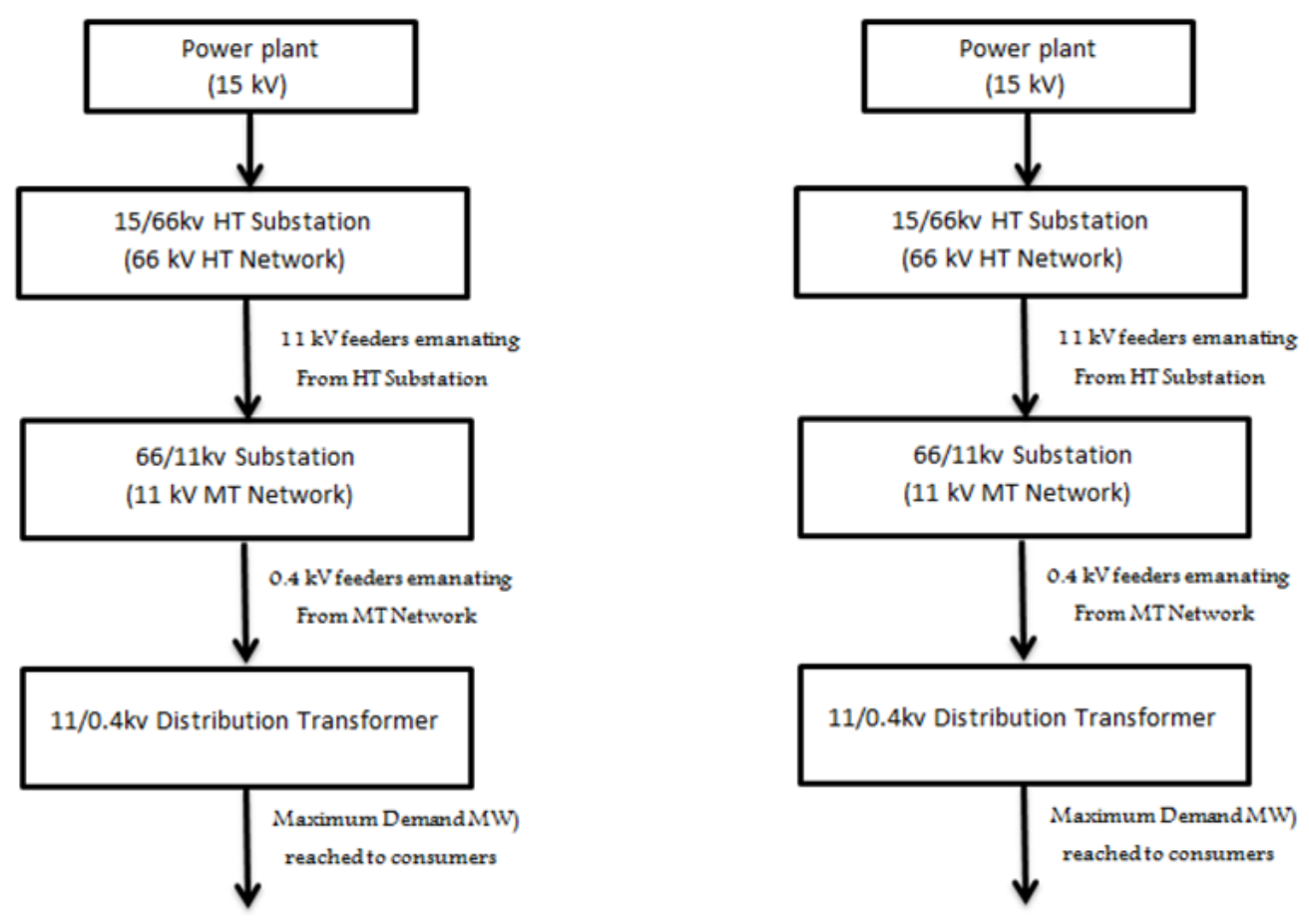

Figure 6. Overview of modelled grid of Abu Hummus in DigSilent

\subsection{Power flow problems}

After the completion of constructing the network we need to obtain the voltage magnitude values at every bus bar. This is obtained by performing load flow. DigSilent offers a selection of calculation methods, including a full AC Newton Raphson method for balanced, unbalanced and a linear DC method. The implemented algorithms exhibit excellent stability and several iteration levels guarantee convergence under all conditions, with optional automatic relaxation and modification of constraints [12,13]. The results obtained after performing load flow problem clearly state that the network has severe low voltage problem. The maximum voltage drop in the network is found to be around $13 \%$ less than the nominal value at $11 \mathrm{kV}$ and $0.4 \mathrm{kV}$ at busbar 2 AL-Mazraa feeders. The overall voltage drops in the network are found to be differing by $0-13 \%$ of the nominal value. Figure 6 shows the individual bus voltage magnitudes in per unit of the $11 \mathrm{kV}$ network of Abu Hummus. The results clearly show that around 67\% of the bus voltage levels in the $11 \mathrm{KV}$ network are less than the nominal value as shown in Figure 7.

Figure 8 shows the individual bus voltage magnitudes in per unit of the $0.4 \mathrm{kV}$ network of $\mathrm{Abu}$ Hummus, the results clearly show that around $69 \%$ of the bus voltage levels in the $0.4 \mathrm{kV}$ network are less than the nominal value. An efficient grid usually has voltage magnitudes in the range of (0.95-1.05p.u). The voltage $11 \mathrm{kV}$ and $0.4 \mathrm{kV}$ networks are $10 \%$ to $15 \%$ less than the nominal value, due to overloading of the transmission lines. 
Figure 9 and Table 1 show the individual bus voltage magnitudes in per unit of the $66 \mathrm{kV}$ networks with available load capacity. Since, voltage magnitudes in $66 \mathrm{kV}$ is within permissible limits (0.95-1.05p.u) [14]. The idea is to minimize the voltage drops in the network by minimizing overloading and to maintain efficient voltage profiles in the network. There are many approaches (i.e. tap-changer transformer and static VAR system) which can be used to maintain the voltage levels under various operating conditions.

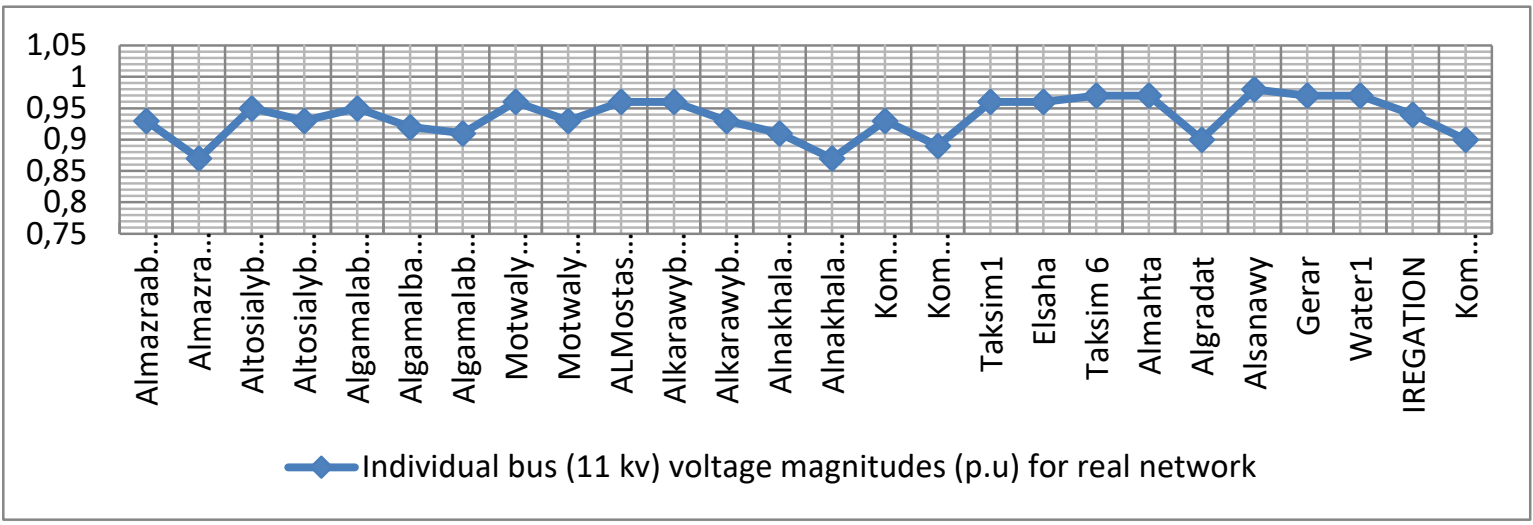

Figure 7. Individual bus (11 kV) voltage magnitudes (p.u) for real network

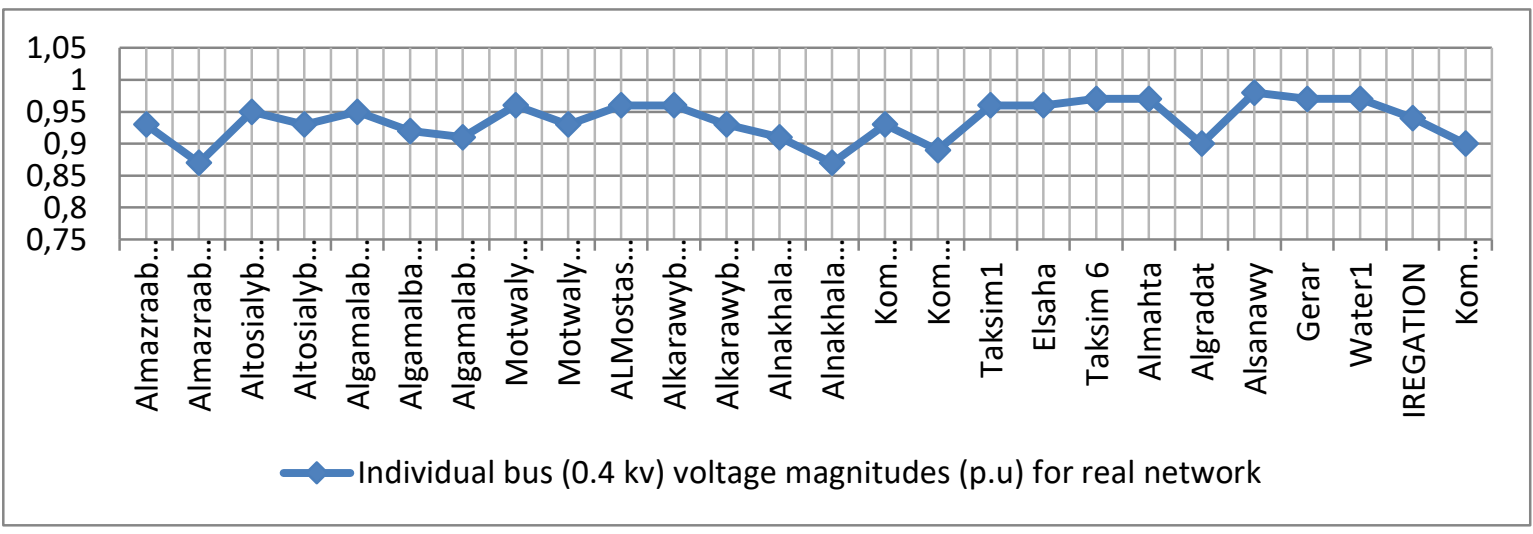

Figure 8. Individual bus $(0.4 \mathrm{kV})$ voltage magnitudes (p.u) for real network

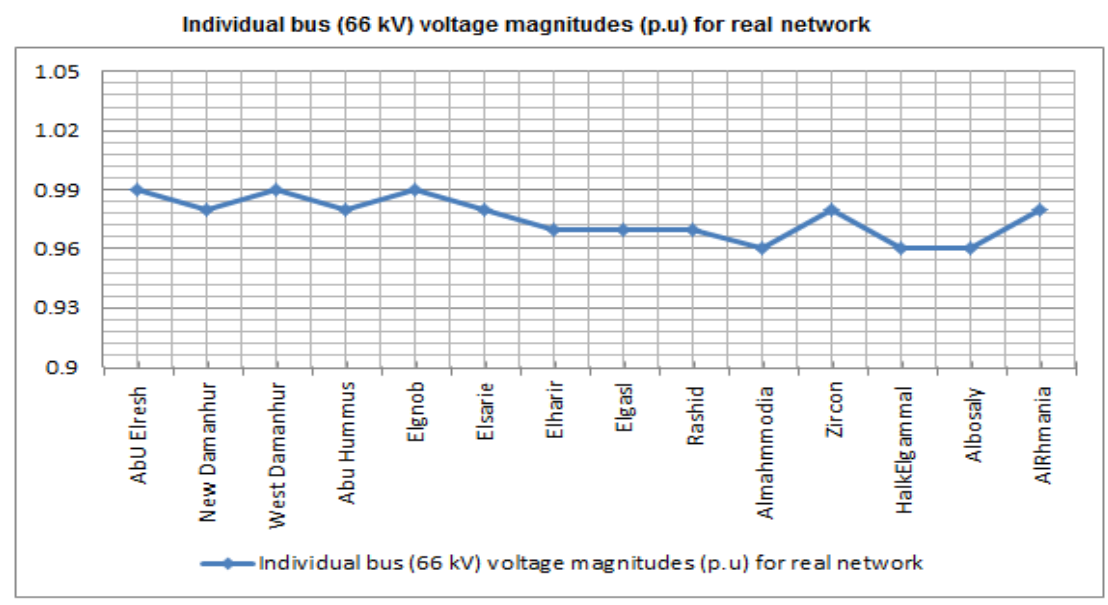

Figure 9. Individual bus $(66 \mathrm{kV})$ voltage magnitudes (p.u) for real network 
Table 1. Voltage magnitudes in per unit of the $66 \mathrm{kV}$

\begin{tabular}{lll}
\hline Feeder Name & load capacity(MVA) & Voltage (p.u) \\
\hline Abu ELrish & 75 & 0.99 \\
New Damanhur & 100 & 0.98 \\
West Damanhur & 80 & 0.99 \\
Abu Hummus & 75 & 0.98 \\
Elgnob & 50 & 0.99 \\
Elsarie & 65 & 0.98 \\
Elharir & 100 & 0.98 \\
Elgasl & 97 & 0.97 \\
Rashid & 50 & 0.99 \\
Mahmoudia & 50 & 0.97 \\
Zircon & 25 & 0.98 \\
HalkElgammal & 75 & 0.97 \\
Albosaly & 25 & 0.97 \\
AlRhmania & 25 & 0.98 \\
\hline
\end{tabular}

\section{VOLTAGE QUALITY IMPROVEMENT USING AUTOMATIC TAP CHANGING TRANSFORMERS}

Voltage can be defined as the difference in electric potential between two points. Regulating the voltage of a transformer is an important requirement that often arises in power systems. It may be needed to supply a desired voltage to the load or to counter the voltage drops due to loads. The voltage is controlled usually by changing the turn's ratio of the transformer. This is done by providing taps in the transformer winding [12-14]. The volts per turn available in large transformers is quite high, hence change of even one turn on the LV side results in large percentage change in the voltage. There are various methods to control the voltage by using a tap changing transformer; e.g. Reactor method of tap changer, Parallel winding, transformer method, Series booster method, Moving coil voltage Regulators and Sliding contact Regulators. In Abu Hummus network tap-changing transformer at various 66/11 KV substation of Abu Hummus, which improved the voltage quality in different feeders of $11 \mathrm{kV}$. Table 2 shows the individual bus voltage magnitudes in per unit of the $11 \mathrm{kV}$ network with available load capacity. Since, voltage magnitudes in $11 \mathrm{kV}$ isn't within permissible limits (0.95-1.05p.u) in different feeders, bus bars of $11 \mathrm{kV}$. To improve the voltage profiles across the network. Table 3 shows the transformer tap-changing parameters in per unit. This method can improve the voltage quality in (ALMazraa 1, Altosialy, Algamala1, 2, Motwaly ALI, Alkarawy, Alnakhala1, Kom Saif1 and Iregation).

Table 2. Voltage magnitudes in per unit of the $11 \mathrm{kV}$

\begin{tabular}{lll}
\hline Feeder\&busbar & Length from substation $(\mathrm{km})$ & Voltage $(\mathrm{p} . \mathrm{u})$ \\
\hline ALMazraa 1 & 8 & 0.93 \\
ALMazraa 2 & 20 & 0.87 \\
Altosialy 1 & 5 & 0.95 \\
Altosialy 2 & 12 & 0.93 \\
Algamala 1 & 3 & 0.95 \\
Algamala 2 & 6 & 0.92 \\
Algamala 3 & 10 & 0.91 \\
Motwaly ALI 1 & 5 & 0.96 \\
Motwaly ALI 2 & 14 & 0.93 \\
ALMostashfa & 6 & 0.96 \\
Alkarawy 1 & 4 & 0.96 \\
Alkarawy 2 & 10 & 0.93 \\
Alnakhala 1 & 5 & 0.91 \\
Alnakhala 2 & 17 & 0.87 \\
Kom Saif 1 & 7 & 0.93 \\
Kom Saif 2 & 16 & 0.87 \\
Taksim1 & 3 & 0.96 \\
Elsaha & 2 & 0.96 \\
Taksim 6 & 3 & 0.97 \\
Almahta & 5 & 0.97 \\
Algradat & 15 & 0.9 \\
Alsanawy & 1.5 & 0.98 \\
Gerar & 4 & 0.97 \\
Water1 & 1 & 0.97 \\
Iregation & 15 & 0.94 \\
Kom alkanater & 20 & 0.9 \\
\hline
\end{tabular}


Table 3. Transformer tap-changing parameters

\begin{tabular}{ll}
\hline Parameter & value \\
\hline Voltage set point & 1.04 \\
Lower voltage Bound & 0.95 \\
Upper Voltage Bound & 1.05 \\
Controlled node & low voltage (secondary side) \\
Additional voltage per tap & $2.5 \%$ \\
Min and Max position & -5 and 5 \\
Copper (cu) losses & 0 \\
Controller time constant & $0.5 \mathrm{sec}$ \\
\hline
\end{tabular}

\subsection{Network by using tap-changer transformer}

Figures 10, 11 and 12 show the comparison of individual bus voltage magnitudes in the $66 \mathrm{kV}$ and $11 \mathrm{kV}$ networks for real data and by using tap-changing transformer at various 66/11 kV substations. For $11 \mathrm{kV}$ and $0.4 \mathrm{kV}$ networks, the results show that by using tap-changing transformer, $90 \%$ of the networks voltage profiles are within the range of 0.95-1.05 but the buses whose voltage magnitudes are below the range of 0.95 are still having the problem of overloading.

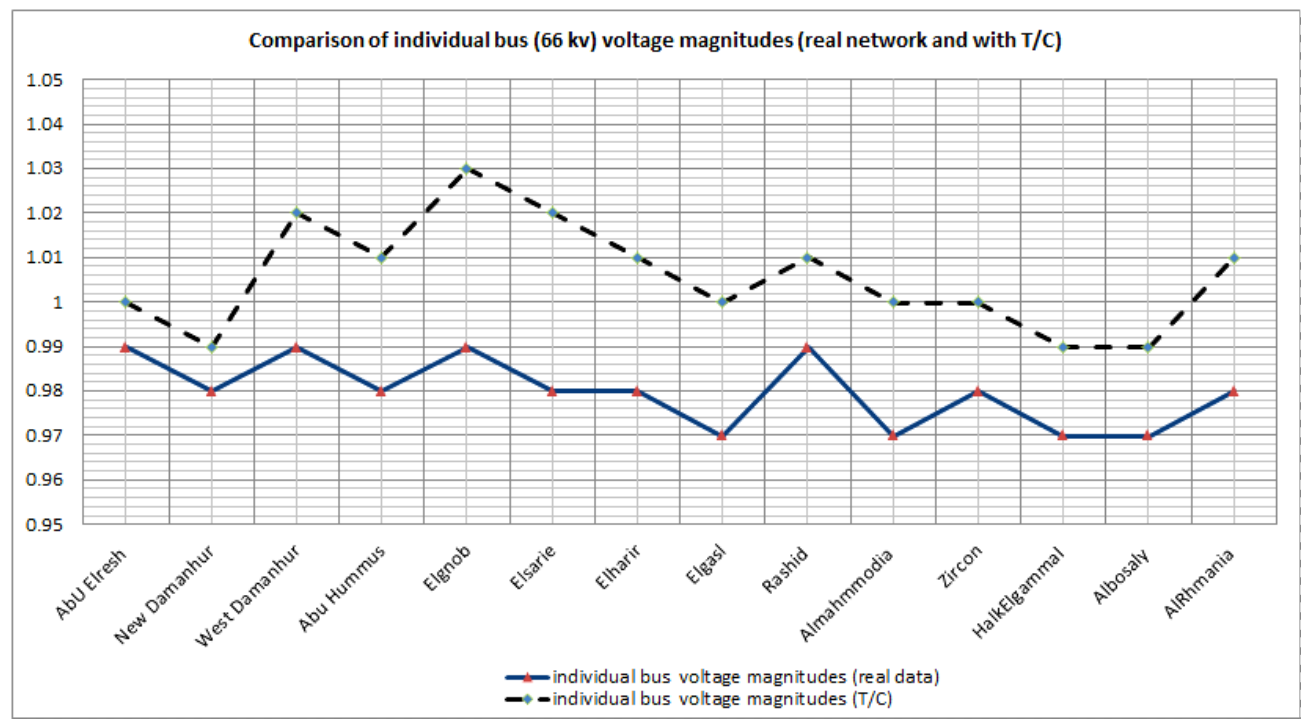

Figure 10. Comparison of individual bus (66 KV) voltage magnitudes (real network and with T/C)

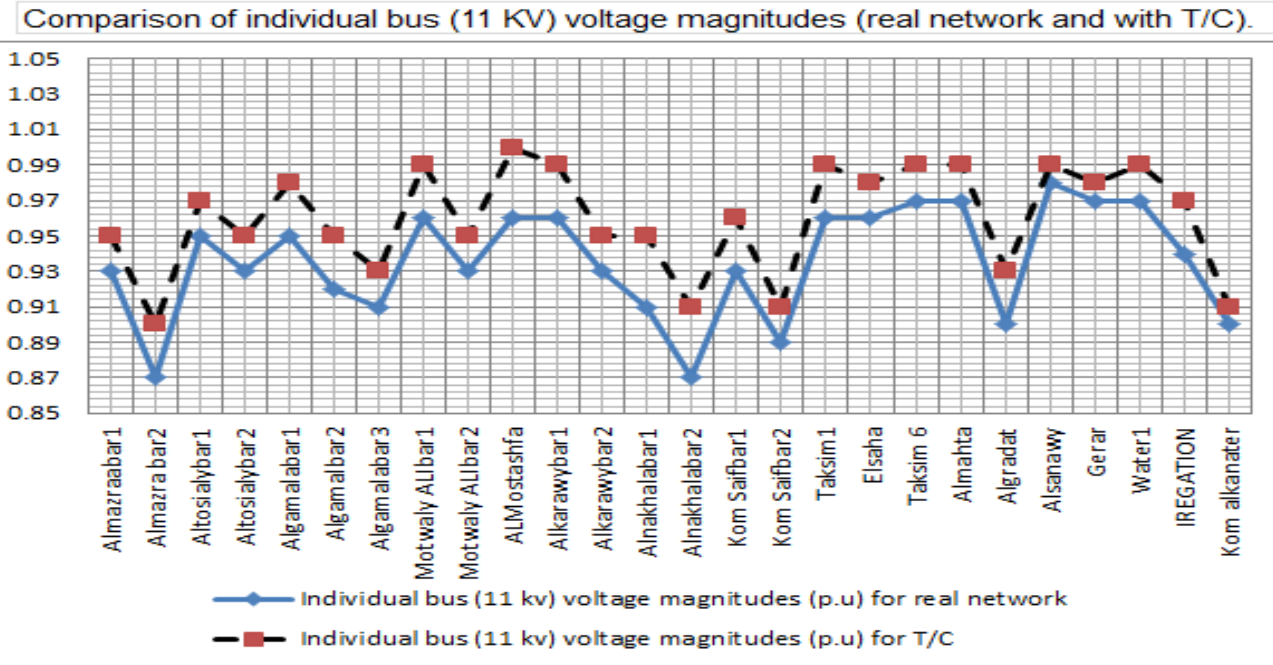

Figure 11. Comparison of individual bus (11 KV) voltage magnitudes (real network and with T/C) 


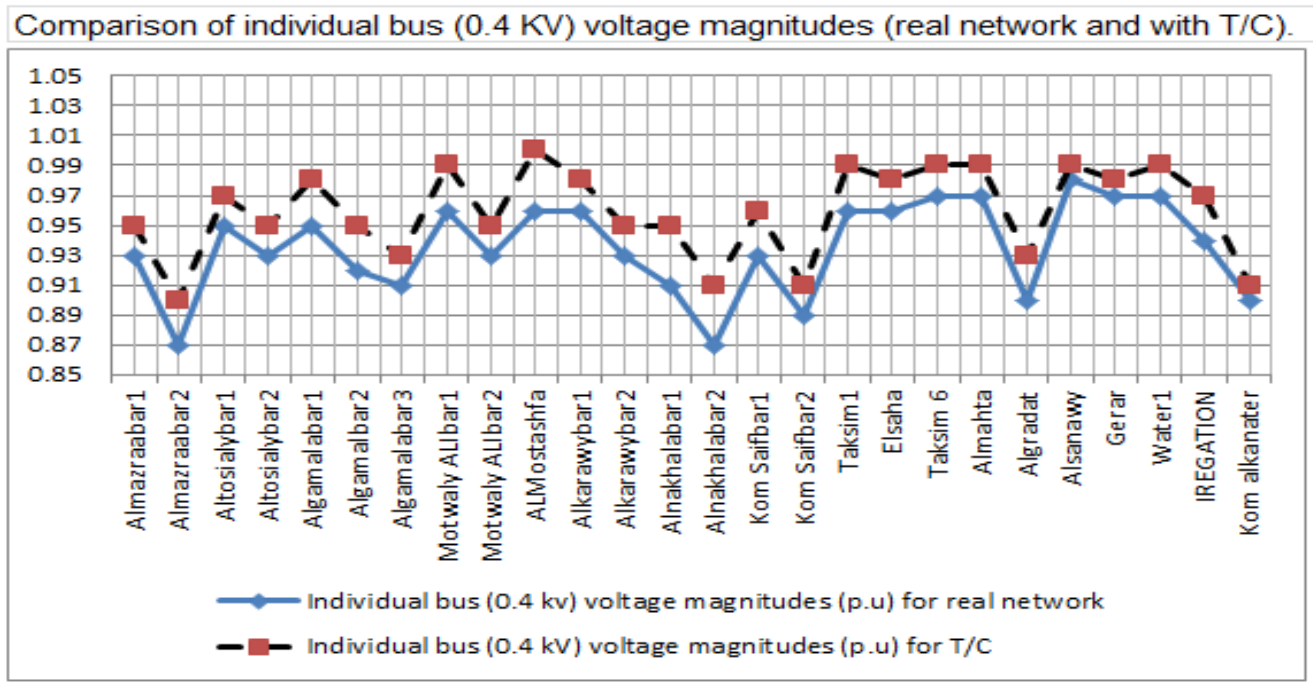

Figure 12. Comparison of individual bus $(0.4 \mathrm{KV})$ voltage magnitudes (real network and with T/C)

\section{STATIC VAR SYSTEM}

For further improvement a static VAR system (SVS) was installed in the network for compensating the reactive power to minimise heavy overloading of the transmission lines by providing sufficient reactive reserves to the network and achieve better voltage profiles. A static VAR system is an electrical system which provides fast acting reactive power on high voltage electricity transmission networks [15]. To improve the transmission capability of the system, not by extension but by improving the transmission quality of the existing system can be achieved by the following factors: stabilizing the system voltage, balancing of system voltage, limiting of over voltages and voltages collapses, damping of oscillations and reduction of reactive power flow. These requirements can be achieved by static VAR compensator which an electrical device for providing fast-acting reactive power compensation on high voltage transmission networks and it can contribute to improve the voltages profile in the transient state and therefore, in improving the quality performances of the electric services [16-18]. A SVC is one of FACTS controllers, which can control one or more variables in a power system [19]. The dynamic nature of the SVC lies in the use of thyristor devices (e.g. GTO, IGCT) [20]. The thyristor, usually located indoors in a "valve house", can switch capacitors or inductors in and out of the circuit on a per-cycle basis, allowing for very rapid superior control of system voltage. The compensator studied in the present work is made up of a fixed reactance connected in series to a thyristor controlled reactor (TRC) based on bi-directional valves- and a fixed bank of capacitors in parallel with the combination reactance-TRC. The thyristors are turned on by a suitable control that regulates the magnitude of the current.

\subsection{Static var compensator}

SVC provides an excellent source of rapidly controllable reactive shunt compensation for dynamic voltage control through its utilization of high-speed thyristor switching/controlled devices [21]. The SVC is typically made up of coupling transformer, thyristor valves, reactors, capacitance (often tuned for harmonic filtering). The main advantage of SVCs over simple mechanically switched compensation schemes is their near-instantaneous response to change in the system voltage. For this reason they are often operated at close to their zero-point in order to maximize the reactive power correction [22-27]. They are in general cheaper, higher-capacity, faster, and more reliable than dynamic compensation schemes such as synchronous compensators (condensers).

\subsection{Control concept of SVC}

An SVC is a controlled shunt susceptance (B) as de-fined by control settings that injects reactive power (Q) in to the system based on the square of its terminal voltage. Figure 13 show a TCR SVC, including the operational concept. The control objective of the SVC is to maintain a desired voltage at the high-voltage bus. In the steady-state, the SVC will provide some steady-state control of the voltage to maintain it the high-voltage bus at a pre-defined level.If the high-voltage bus begins to fall below its set point range, the SVC will inject reactive power $\left(Q_{\text {net }}\right)$ in to there by increasing the bus voltage back to its net. 


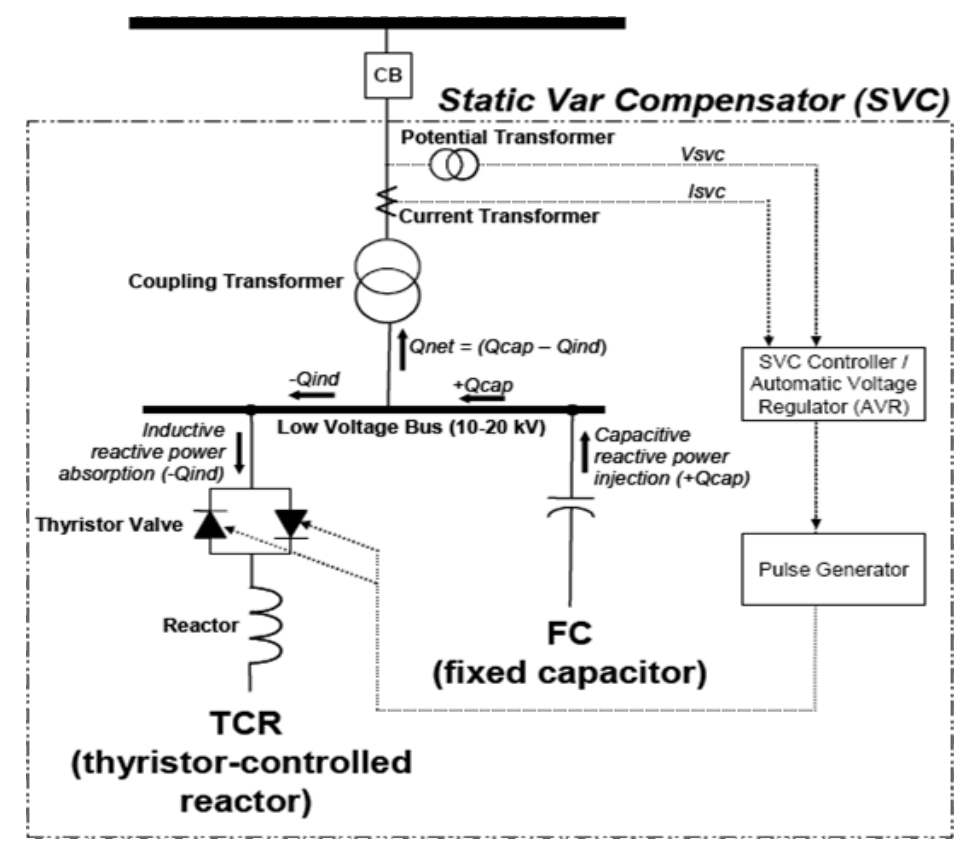

Figure 13. SVC with control concept

\subsection{Working of a static VAR system}

DigSilent power factory is a tool which provides highly integrated graphical one line interface. The tool contains a graphics board in which all the devices required for modelling a power system network are enlisted. This makes it easy to access the components required for modelling the network. The static VAR system (SVS) is used to improve the voltage quality of Abu Hummus network by providing enough reactive reserves. The place where SVS needs to be installed must be accurate so as to achieve best voltage profiles and system stability. For this, the entire network was exploited for installing SVS and came up with a possible solution where SVS can be installed. The SVS is connected on the $11 \mathrm{kV}$ side of $66 / 11 \mathrm{kV}$ Abu Hummus substation. The SVC Parameters considered: thyristor controlled reactance maximum limit (TCR) equal 120Mvar, thryristor shunt capacitance (TSC): maximum number of capacitors of 6 (20Mvar/Capacitor) and the amount of reactive power injected into the network at bus ( $11 \mathrm{kV}$ Abu Hummus) is $\mathrm{Q}$ equal 104.8Mvar. (Automatically generated value from load flow problem).

\subsection{Results network by static VAR system}

Figures 14 and 15 shown in the comparison of the individual bus voltage magnitudes a cross the $66 \mathrm{kV}$ and $11 \mathrm{kV}$ networks of Abu Hummus for real network, with tap-changer transformer and with static VAR system.

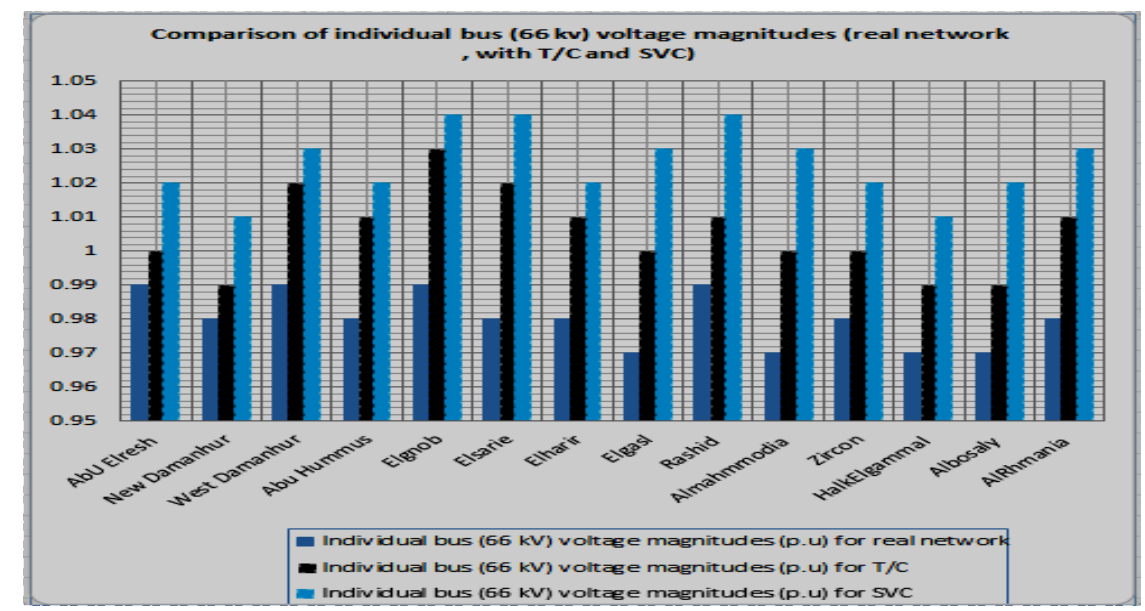

Figure 14. Comparison of individual bus $(66 \mathrm{kV})$ voltage magnitudes 


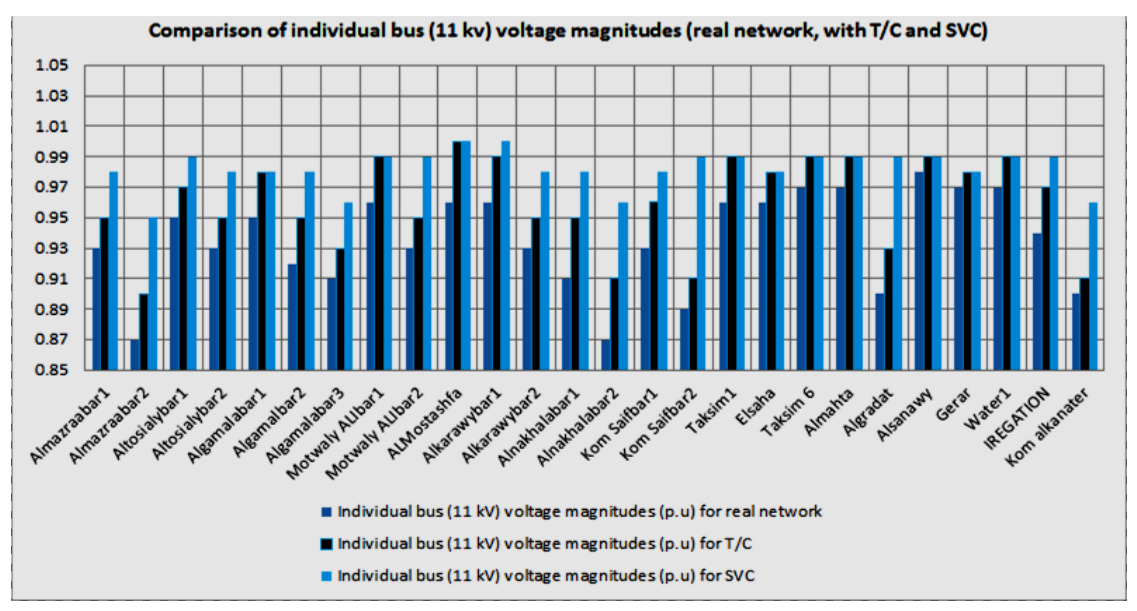

Figure 15. Comparison of individual bus $(11 \mathrm{kV})$ voltage magnitudes

\section{CONCLUSION}

The paper mainly deals with investigating the voltage quality of the city Abu Hummus and problems associated with it. The main idea of this paper is to improve the voltage quality of the existing network, without making any further extensions to the network. For this the transmission network of Abu Hummus was modelled by DigSilent software tool and performed load flow operation to obtain individual bus voltage magnitudes. From the initial results obtained by performing load flow problem, it could be shown that the electrical network of Abu Hummus has severe low voltage problem, especially in the $11 \mathrm{kV}$ and $0.4 \mathrm{kV}$ networks due to heavy over loading of network elements. The voltage at many places differs by $10 \%-13 \%$ of the nominal voltage. This is attributed mainly due to technical losses. After obtaining the initial results by performing load flow problem certain basic methods were adopted to improve the voltage quality of the network and reduce heavy line loadings. First method: to improve the voltage levels in the network by using automatic tap-changing transformers at substation in the city. This helped to improve $90 \%$ of the networks voltage quality. Second method: to obtain better voltage profiles, to optimise the reactive power of the network by installing a static VAR compensator. For this, the entire network of Abu Hummus was exploited and found possible solutions to install the SVC. Finally, the approaches used above help to improve the voltage quality of the existing Abu Hummus network. From the static results achieved it can be clearly suggested that the approaches used are one of the best possible and suitable solutions to improve efficiency of the existing Abu Hummus electrical network, keeping in view the problems the grid has. The results achieved helps to minimise the continuous overloading of the network elements, by providing enough reactive reserves and mantain the voltage quality of the network.

\section{REFERENCES}

[1] Egyptian Electricity Holding Company Annual Report - 2010/2011.

[2] Egyptian Electricity Holding Company Annual Report - 2017/2018.

[3] National strategy of renewable energy to Egypt, [Online]. Available: http://www.nrea.gov.eg/english1.html.

[4] B. Vahidi, M. R. Tavakoli and W. Gawlik, "Determining the parameter of turbines model," IEEE Trans Power Syst. vol. 22, no. 4, pp. 1547-1553, 2007.

[5] IEEE Committee Report, "Dynamic models for steam and hydro turbines in power system studies," IEEE Trans. Power Appl. Syst. vol. 92, no. 6, pp. 1904-1915, 1973.

[6] N. Pathak, A. Verma and T. S. Bhatti, "Automatic generation control of thermal power system under varying steam turbine dynamic model parameters based on generation schedules of the plants," The Journal of Engineering, pp. 1-13, 2016.

[7] T. Yu and J. Yuan, "Modeling of the coal-fired utility boiler in a thermal power plant based on. macro energy balance," Advanced Materials Research, pp. 732, pp. 29-36, 2013,

[8] G. J. Van Wylen, R. E. Sonntag and C. Borgnakke, "Fundamentals of classical thermodynamics," fourth ed., Wiley, New York, 1998.

[9] Han, Zhen-Xiang, and Yi-Jia Cao, "Power system control based on voltage risk [J]," Power system technology, vol. 9, 2004.

[10] DIgSILENT PowerFactory, DigSilent. [Online]. Available: www.digsilent.de/Software/DIgSILENT PowerFactory.

[11] DigSilent, "Digsilent Power factory manual version,"

[12] M. A. Omara and I. A. Nassar, "Voltage quality in delta Egypt network and its impact in oil industry," Energy Reports, vol. 5, pp. 29-36, 2019. 
[13] I. A. Nassar, Abdella, M. M., "Effects of increasing wind and solar power energy on the voltage stability and losses of the egyptian power system," 20th International Middle East Power Systems Conference, 2018.

[14] I. A. Nassar and M. Abdella, "Parameters calculation of thermal power plant dynamic model using steam cycle data," Thermal Science and Engineering, Published by Elsevier Ltd, vol. 9, pp. 259-265, 2018.

[15] H. Pesch, S. Ranade, M. Schubert and P. Sieber, "Static VAR-Compensators for stabilizing traction and transmission systems in South Africa," AEG Germany, 2007.

[16] J. Sridevi, J. Amarnath and G. Govinda Rao, "Zonal power quality improvement using static var compensator for an indian utility system," International Journal of Engineering Research, vol. 2, no. 3, pp. 1320-1325, 2012.

[17] I. A. Nassar, "Reactive power control in power systems using neural networks," Master Thesis, Al-Azhar University, 2004.

[18] T. J. E. Miller, "Reactive Power Control in Electric Systems," Wiley \& Sons, New York, 1982.

[19] J. J. Paserba, "How FACTS controllers benefit AC transmission systems," IEEE Power Engineering Society General Meeting, Denver, pp. 6-10, 2004.

[20] P. Lips, "Semiconductor power devices for use in HVDC and FACTS controllers," CIGRE Technical Brochure, vol. 112, 1997.

[21] A. E. Hammad, "Comparing the voltage control capabilities of present and future VAR compensating techniques in transmission systems," IEEE Trans. Power Delivery, vol. 11, no. 1, pp. 475-484, 1996.

[22] J. Verseille, "Voltage and reactive control," Electra, no. 173, pp. 115-143, 1997.

[23] C. Balu and D. Maratukulam, "Power system voltage stability," McGraw Hill, 1994.

[24] P. Kundur, "Power system stability and control," McGraw Hill, 1994.

[25] I. A. Nassar and M. M. Abdella, "Impact of replacing thermal power plants by renewable energy on the power system," Thermal Science and Engineering Progress, 2018.

[26] I. A. Nassar, Salaheddin Al Ali and H. Weber, "Effects of Increasing Intermittent Generation on the frequency control of the European Power System," 19th IFAC World Congress (IFAC WC 2014), pp. 24-29, 2014.

[27] M. A. Omara and I. A. Nassar, "Voltage quality in delta Egypt network and its impact in oil industry," Energy Reports, vol. 5, pp. 29-36, 2019.

\section{BIOGRAPHIES OF AUTHORS}
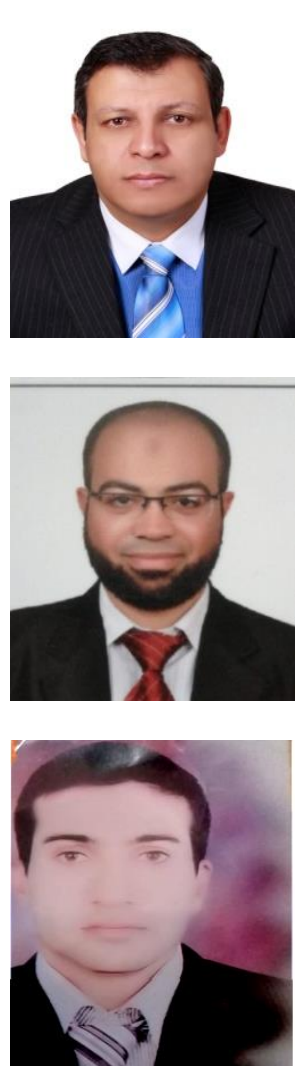

Ibrahim Nassar received the B.Sc. (1999) \&M.Sc. (2004) degrees in Electrical Engineering from Al-Azhar University. Since (2001), he has been at faculty of Engineering, Al-Azhar University.He received his $\mathrm{PhD}$ in Rostock University, Germany (2011). Currently he is associate professor at faculty of Engineering, Al-Azhar University, Egypt.

Mohammed Sh. Seif received his B.Sc. degree at 2006. He joined the staff of the Electrical Engineering Department, Al-Azhar University as a researcher and teaching assistant from 2007 to 2018, during this time, he received the M.Sc. and the Ph.D. degrees in Electrical power engineering from Al-Azhar University, Cairo, Egypt in 2012 and 2018 respectively.,currently an Associate Professor with the Department of Electrical Engineering, Al-Azhar University

Mahmoud Elattar received the B.Sc. (2011) in Electrical Engineering from Al-Azhar University, From 2011 till 2012, he worked in Ghazal and textile factory in 10th of Ramadan city and since 2013 till now he works in Beheira Electricity Distribution Company Ministry of Electricity and Renewable Energy 